\title{
Anti-relativist draws others into the whirlpool
}

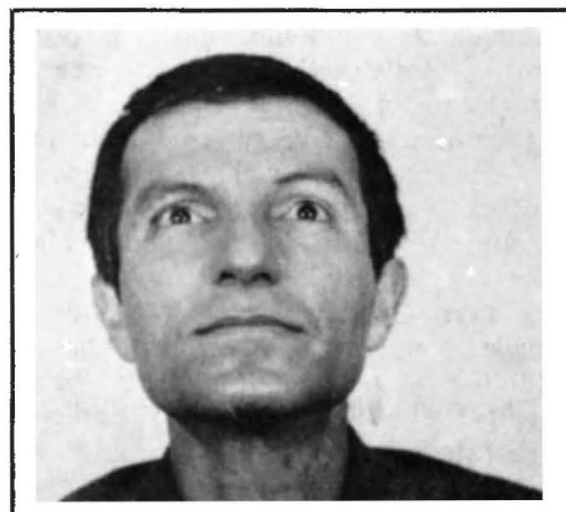

Stefan Marinov
$O$ father Galileo, cunning one and wise,

Thy trial persisteth still even from age to age;

Moralist and philosopher try thee, the fool eke tries,

And everyone who counts himself a learned sage.

So wast thou then a coward, valourless, without honour,

Thyself knowing the truth, to spit on truth, deride,

Saving thy mortal frame, to fraud to sing "hosanna",

Before all men to trample thine honour and thy pride.

Holy lord of the spirit, my teacher wise and dear,

Is the common herd worth our torments and our blood.

Shout yourself hoarse-no sound will reach its blunted ears;

Throw your heart at its feet-onward it still doth plod.

So, doctors, I bow and swear: "There is no absolute space! All I affirmed is lunacy-bring on your drugs apace!"
RESTRICTIONS on scientific correspondence in the Soviet Union and its satellites have, over recent years, become familiar-the classic study of the problem being The Medvedev Papers. One of the most curious byproducts of the system is the recent appearance, in Belgium, of an antirelativistic tract with the lofty title Eppur si Muove and a preface signed by no less a person than A. D. Sakharov-presumably the dissident academician of that name. In fact, as the author of the book, Stefan Marinov, himself admits, Sakharov never wrote such a preface; Marinov claims, however, that Sakharov gave him permission to append his name to a preface written by Marinov on his behalf.

Although this may appear at first glance somewhat a trivial matter-that of a 'fringe scientist' trying to gain the backing of an eminent member of the orthodox community-the appearance of the preface could have considerable implications for Academician Sakharov. The various campaigns launched against him within the Soviet Union regularly imply that he has 'abandoned' or 'betrayed' science for 'so-called dissidence', and his apparent endorsement of a scientific theory which he himself does not hold, simply because its author was himself in trouble with the authorities in his own country, could add valuable fuel to this debate. The history of this curious preface is therefore worth looking into.

Stefan Marinov first made his appearance in the western media in the autumn of 1976, when large advertisements began to appear for a conference on 'Space and Time Absoluteness' the following May, on his initiative. A certain 'A. D. Sacharov' of Moscow was listed, variously, as Chairman or Patron of the conference. This surprising announcement led to considerable speculation, and a general consensus of opinion that it could not be Academician Sakharov who was meant. Even the difference in spelling was cited to support this idea, by those who did not realise that the Russian name CAXAPOB would, in certain transliteration systems, be rendered as 'Sacharov'. In fact at the time of the announcement, Marinov and his western supporters were still trying to contact Academician Sakharov by telephone, to ask for his consent, and were approaching anyone (the present author included) whom they felt might be able to make such a contact.

Marinov's next attempt to contact Sakharov came the following spring. His magnum opus, refuting the theory of relativity and all associated physics, was ready for publication, and he wished Sakharov to provide a preface. Having still failed to contact Sakharov over the Varna Conference, Marinov wrote the preface himself, distributed copies to possible contacts with the request that they forward them to Sakharov, and added a covering letter which, in the manner of a student applying for an exeat, said that unless he heard to the contrary, he would assume that he had Sakharov's permission to proceed. In one version of the covering letter, he added a brief self-portrait. "As far as I know, I am the unique 'dissident' in my country (once in a prison, twice in a loony bin). I descend from an old family of intellectual communists, and I am a Marxist (I have even written a book on mathematical political economy-in Russian-and I have a translation in Serbo-Croatian). My opinions are most close to those of Roy Medvedev."

Marinov was soon to be back in the mental hospital for a third time. At the end of April 1977, telegrams signed 'Marinov' were sent to journalists and others who had any connection with the Varna conference, cancelling it on the grounds that an earthquake was expected. The immediate assumption, that Marinov had taken this means of cancelling an event which had no supporters, proved false. Marinov had been removed to hospital by the authorities, who had then notified in his name all those on his address list. News of this reached the West in May, but journalists were earnestly requested by his friends not to publish, since this would endanger his life. In all events, once the critical dates of the planned conference were over, Marinov was released, and in late summer he was allowed to emigrate. He settled in Belgium.

In October, 1977, the news-magazine Pourquoi Pas? carried a massive article on Marinov, "The Scientist who came in from the cold', with a reprint of the 'Sakharov' preface. This, allowing for translation and editorial omission, was identical with Marinov's own draft. Although it seemed highly unlikely that Sakharov would have lent his name, I decided to seek confirmation on this point. It is virtually impossible to get a letter through to Sakharov, and direct telephone contact is likewise a random matter with minute probability of success. Nevertheless, the message reached Sakharov by two channels, and two answers were received. One, via a physicist, ran 'Academician Sakharov knows of the book, but did not wish to be associated with it, as he does not agree with the theory!' The other, less formal message, was transmitted as 'Andrei Dmitrievich says: "The man's a nut-case ( $p$ sikh), but I wouldn't want to condemn anyone to a mental hospital!", '.

At the end of November, Marinov turned up, uninvited, at the Science Session of the Venice Biennale. Asked about the preface, he maintained that a 'courier', described as 'an eminent physicist' and a 'young girl', had taken the book to Sakharov who received the courier, expressed sympathy for Marinov's plight, and agreed to 'think about' the matter of the preface. Sakharov is well known for his kindness and compassionate interest in all those in trouble; and he probably meant simply to give an expression of personal sympathy coupled with a polite refusal 
to involve himself with Marinov's theories. Unfortunately, Marinov construed this as consent to have his signature added to the preface. Although a number of people entreated Marinov to withdraw it, he refused, saying that as it had appeared in Pourquoi Pas? it was now too late to do so. Moreover, he needed Sakharov's name to sell the book; unless he could sell 5,000 copies at $\$ 20$ each he could not get the money he needed to carry out the experiments described in it. (One presumes he meant 'replicate'.) A long and hysterical telex was dis- patched to Sakharov c/o the Soviet Academy, and copies circulated among the Biennale journalists. Sakharov at that time was not even in Moscow; he and his wife were staging a sit-in in a Siberian labour camp where her nephew Edvard Kuznetsov, the dissident writer, had been refused his regular visit from the Sakharovs. At the time of writing, Marinov is still trying to get a message through to Sakharov.

Marinov's experiences in defence of his theories have undoubtedly made him only the more adamant in maintaining them. His poems imply that his incarceration in the mental hospital was on account of his theories (see sonnet opposite). Clearly he is willing to take any means to promulgate them, even resorting to 'short cuts' when no answer is forthcoming. This is almost certainly not the first such occurrence in the long history of East European censorship-a number of very curious documents have reached the West from time to time. The whole episode is yet another illustration of the curious situations which can arise when governments restrict the freedom of scientific contact and correspondence.

Vera Rich

\section{Polishing a tarnished image}

LAST Wednesday the centre of Washingtion was brought to a standstill by a demonstration of angry farmers demanding " $100 \%$ parity" — a price for their products that would give them the buying power of 65 years ago, when agricultural prices were at their peak. That same afternoon, a group of congressional employees was given a seminar on "government's role in scientific research" by a group of distinguished biomedical scientists, including three Nobel laureates-Anthur Kornberg, George Palade and James D. Watson-and the heads of some of America's leading biomedical research institutions and medical schools.

The style was different from that of the farmers, but the demand was very similar: a return to the levels of funding that basic research in the biological and medical sciences enjoyed in the relatively halcyon days of the late 1960s.

The case that the scientists presented during a well-organised two-day visit to Washington-which included private meetings with congressmen and members of the administration, as well as public hearings before the appropriations committees of both the Senate and the House-was straightforward. Basic research, they claimed, is grossly underfunded in comparison with applied resarch-it is in a chronic state of instability and lacks the means of training a new generation of scientists.

"We are here to draw to the attention of our legislators the importance of basic biological research in the solution of major elements of our nation's health cane problems," Dr Mahlon Hoagland, President of the Worcester Foundation for Experimental Biology, and a major organiser of the Washington visit, told Senator Thomas Eagleton's appropriations subcommittee on the budget of the Department of Health, Education and Welfare.

On the surface, the argument was about money; the report in the New York Times carried the not unfamiliar headline "Scientists plunge into lobbying for mone medical research aid". And the scientists presented a carefullyquantified list of grievances.

For an example they claimed that there has been an $18 \%$ drop in the total amount of federal funds spent on basic research since 1967, and a reduction of $17 \%$ in support for scientistinitiated grants awarded by the National Institutes of Health (NIH) between 1967 and 1975 .

Between 1967 and 1977 there was a decrease in the proportion of grants funded to grant applications submitted from $53 \%$ to $33 \%$, they told the subcommittee. And the scientists also pointed out that there has been a decrease in funds for training young scientists from $18 \%$ of the NIH's extra mural budget in 1967 to $6.8 \%$ in 1976 .

The demands, too, were specific. The group said that it wanted the NIH to be provided with an across-the-board increase in funding of $10 \%$ in the fiscal year 1979 to compensate for the effects of inflation, and a neturn to 1967 levels in both scientist-initiated grants for basic research (then $61 \%$ of the NIH external budget) and the biomedical research support grants system (then $7 \%$ ).

In addition, they requested an extra $\$ 100$ million a year for five years (an increase of almost $50 \%$ over the current budget) to be added to the budget of the National Institutes of General Medical Science, the NIH's basic research institute through which many biomedical research activities in universities and medical schools are funded.

Yet the visit to Washington was not only - or indeed primarily - about money. Indeed on purely statistical grounds, the case that the scientists presented lay open to criticism. It was pointed out, for example, that by taking the 1967 figure as a bench-mark, a year in which research funding is generally reckoned to have reached the peak of the 1960 s expansion, figures for subsequent years appear particularly-and perhaps artificially-bad. And figures presented purely as percentages obscure the almost 300\% increase in total funding for NIH.

Furthermore both NIH and President Carter's Office of Science and Technology Policy have shown themselves to be aware of the current problems facing the basic research community: After what everyone agrees was a bleak period between 1967 and 1972, funds for basic resarch have been picking up, and will continue to do so if Congress accepts the suggested increases in President Carter's budget proposals presented this week.

But behind the dispute over financial resources lies a deeper issue of concern to the scientific community, the public image of science, and in particular of basic science on which Congress's willingness to provide additional funds ultimately stands.

In recent years, just as the debate over the implications of the Rothschild Repont in Britain have reflected growing demands for the "relevance" of medical science, so similar tendencies in the US have given rise to what has been called the "disease of the month" menitality with a philosophy that medical science should be primarily directed towards curing, rather than understanding a disease.

In this climate, as funds have come pouring in for research into diseaserelated programmes such as cancer and heart disease, resulting in the total NIH budget increasing from about $\$ 1,000$ million to over $\$ 2,500$ million in seven years, so basic research has-in relative terms-lagged behind, and the process of scientific discovery has, it is claimed, been both distorted and delayed.

In the eyes of many basic scientists the villain of the piece is the so-called "war against cancer" launched in 1971 